\title{
Poly(epsilon caprolactone)/clay nanocomposites via host-guest chemistry
}

\author{
Mustafa Arslan ${ }^{\mathrm{a}, \mathrm{b}}$, Mehmet Atilla Tasdelen ${ }^{\mathrm{a}, \mathrm{c}, *}$, Tamer Uyar ${ }^{\mathrm{d}}$, Yusuf Yagci ${ }^{\mathrm{a}, \mathrm{e}, *}$ \\ ${ }^{a}$ Department of Chemistry, Faculty of Science and Letters, Istanbul Technical University, Maslak, TR-34469 Istanbul, Turkey \\ ${ }^{\mathrm{b}}$ Department of Chemistry, Art and Science and Letters, Kirklareli University, TR-39000 Kirklareli, Turkey \\ ${ }^{\mathrm{c}}$ Department of Polymer Engineering, Faculty of Engineering, Yalova University, TR-77100 Yalova, Turkey \\ ${ }^{\mathrm{d}}$ UNAM-Institute of Materials Science and Nanotechnology, Bilkent University, TR-06800 Ankara, Turkey \\ e King Abdulaziz University, Center of Excellence for Advanced Materials Research (CEAMR) and Chemistry Department, Faculty of Science, P.O. Box 80203, \\ Jeddah 21589, Saudi Arabia
}

\section{A R T I C L E I N F O}

\section{Article history:}

Received 8 May 2015

Received in revised form 4 August 2015

Accepted 9 August 2015

Available online 10 August 2015

\section{Keywords:}

Cyclodextrin

Host-guest chemistry

Nanocomposites

Organoclay

Ring-opening polymerization

Self-assembly

\begin{abstract}
A B S T R A C T
Cyclodextrin-modified montmorillonite (MMT-CD) has been prepared from commercial montmorillonite clay (Closite 30B) containing two hydroxyl groups by reacting succinic anhydride through esterification. Poly(epsilon caprolactone) (PCL)/clay nanocomposites are prepared by host-guest chemistry between MMT-CD as host and PCL, hydrophobic polymer as guest. The structures of the intermediates and final nanocomposite are investigated in detail by FT-IR XRD, TEM, DSC and TGA measurements. The intercalated/exfoliated morphologies are determined by combined XRD and TEM analyses. Thermal stabilities of all nanocomposites are improved by the addition of MMT-CD compared to the neat polymer. The DSC data confirm that the crystallinity of PCL is slightly increased by increasing clay loading.
\end{abstract}

(c) 2015 Elsevier Ltd. All rights reserved.

\section{Introduction}

Combination of organic and inorganic structures within a single material at nanoscopic level is one of the most effective approaches for producing new materials with advanced properties [1]. Generally, inorganic nanoparticles have been incorporated into common organic polymers to generate a new class of hybrid nanocomposite materials that combine the desirable properties of inorganic nanoparticles (e.g. rigidity, high strength, electrical conductivity, thermal and oxidative stability) with the advantages of organic polymers (e.g., processability, flexibility, toughness and cost). The significant improvements are due to the strengthened interfacial interactions between polymer chains and nanoparticles, which are well dispersed in the polymer matrix. A wide range of nanoparticles such as, clays, carbon nanotubes, graphites, polyhedral oligomeric silsesquioxane (POSS) and metal oxides are currently available and used for preparing polymer nanocomposites. The silicate-based clays are among the most widely studied inorganic nanoparticles because of their abundance, price and well-known intercalation chemistry [2-4]. Up to date, several strategies have been considered for the preparation of polymer/clay nanocomposites with homogenous dispersion of clay layers, namely, solution exfoliation, melt intercalation, in-situ polymerization, and template synthesis [5]. Depending on the interfacial interactions and mode of mixing of the polymer and clay layers, three distinct morphologies can be obtained in the system; unintercalated (or microcomposite), intercalated (and/or flocculated), or exfoliated (or delaminated) [6]. In-situ polymerization involves the swelling of the organomodified

\footnotetext{
* Corresponding authors at: Department of Chemistry, Faculty of Science and Letters, Istanbul Technical University, Maslak, TR-34469 Istanbul, Turkey. E-mail addresses: tasdelen@yalova.edu.tr (M.A. Tasdelen), yusuf@itu.edu.tr (Y. Yagci).
} 
clays in liquid monomers, which diffuse in between the clay platelets [7]. The subsequent polymerization, which can be initiated by external stimulations such as thermal [8-15], photochemical [12-22], or chemical activation [22-26], triggers the delamination of clay layers and hence the nanocomposite formation containing intercalated or exfoliated structures. This approach provides better exfoliation compared to melt and adsorption methods [27]. Recently, click chemistry reactions, and in particular the copper-mediated 1,3-dipolar [3+2] cycloaddition between azides and alkynes (CuAAC) have been applied for the preparation of polymer/clay nanocomposites. In this approach, the exfoliation is rooted in the functional units of the intercalant that readily react with the antagonist groups of the preformed polymers [28-31]. The azide and alkyne partners can each be incorporated in either the clay surface or polymer chain. The quantitative efficiency of click reaction coupled with tolerance to a wide variety of functional groups and reaction conditions make this coupling process highly attractive for the nanocomposite preparation. Not only but also, the thiol-ene and atom transfer nitroxide radical coupling click reactions have been employed to prepare polymer/clay nanocomposites. Spectroscopic and microscopic investigations revealed that nanocomposite formations with mixed morphologies including intercalated layers with a non-uniform separation and exfoliated single layers isolated from any stacks were successfully attained. The multiple hydrogen-bonding interactions based on 2-ureido-4[1H]pyrimidinone system have been also utilized to fabricate exfoliated silicate polymer/clay nanocomposites [32]. The multiple hydrogen-bonding interactions between intercalated 2-ureido-4[1H]pyrimidinone (UPy)-functionalized organoclay and UPy-end functionalized polymers have been exploited to delaminate the clay tactoids resulting in the formation of nanocomposites.

Cyclodextrins (CD)s are cyclic oligosaccharides and classified according to their number of glucopyranose units $(\alpha-$ cyclodextrin ( 6 units of glucopyranose), $\beta$-cyclodextrin ( 7 units of glucopyranose) and $\gamma$-cyclodextrin ( 8 units of glucopyranose)) [33]. The most important feature of such cyclic structures is a hydrophobic inner cavity and a hydrophilic outer surface, hence their ability to form non-covalent inclusion complexes with organic [34], inorganic [35], biological molecules [36] or supramolecular aggregates [37,38]. The main factors acting as driving force to form host-guest complexes and their stabilities are hydrophobic forces, the sizes of molecules/cavity and the guest properties. The host-guest chemistry provides a valuable platform for the synthesis of various supramolecular macromolecular architectures [39] including stars [40], hydrogels [41], polymer brushes [42] with other molecules and polymers [43-45]. There are few reports on the preparation of organomodified clays containing cyclodextrin units in the literature [46-53]. However, in these study only inclusion complexes with various low-molecular-weight compounds such as benzene [50], benzoic acid [46], toluene [46,49,50], cetylpyridinium chloride [47], crystal violet [48], ethylbenzene [50], menthone [49], mimonene [49], naphthalene [50] pyrene [52], tetrachloroethylene [50], 1,2,3trichlorobenzene [50], trichloroethylene [50] and o-xylene [50] were investigated. To the best of our knowledge, no report is currently available in the literature regarding the preparation of polymer/clay nanocomposites using host-guest type complex system.

In this study, firstly the cyclodextrin as host has been introduced to the hydroxyl groups of commercial montmorillonite clay (MMT- $\left.\left(\mathrm{CH}_{2} \mathrm{CH}_{2} \mathrm{OH}\right)_{2}\right)$ by reacting a cyclic anhydride through esterification [54]. Poly( $\varepsilon$-caprolactone) (PCL), a wellknown biodegradable polymer, is employed as guest polymer, which is able to form inclusion complexes with cyclodextrin. The host-guest type complex formation of the intercalated cyclodextrine-functionalized clay (MMT-CD) and PCL could gradually push the layers apart, leading to delamination of clay tactoids. The obtained PCL/MMT nanocomposites have been characterized by X-ray diffraction (XRD) spectroscopy, thermogravimetric analysis (TGA), differential scanning calorimetry (DSC), and transmission electron microscopy (TEM). The influence of molecular weight of PCL and clay loadings on the microstructure and thermal properties of PCL/MMT composites is also investigated. The mild reaction condition coupled with tolerance to a wide variety of convenient polymers make this process highly attractive for the nanocomposite preparation.

\section{Experimental}

\subsection{Materials}

An organo-modified clay, Cloisite 30B [MMT- $\left(\mathrm{CH}_{2} \mathrm{CH}_{2} \mathrm{OH}\right)_{2}$ ] was purchased from Southern Clay Products (Gonzales, TX, USA). The organic content of organo-modified MMT, determined by thermogravimetric analysis (TGA), was 21 wt\%. The clay was dried under vacuum at $110{ }^{\circ} \mathrm{C}$ for $1 \mathrm{~h}$ before use. Succinic anhydride (SA, Merck, 99\%), 4-( $N, N$-dimethylamino) pyridine (DMAP, Merck, 99\%) were purchased from Merck. Chloroform-d ( $\mathrm{CDCl}_{3}, 99.8$ atom\% D), deuterium oxide ( $\mathrm{D}_{2} \mathrm{O}, 99.9$ atom\% $\left.\mathrm{D}\right)$ and dicyclohexylcarbodiimide (DCC) were provided by Sigma-Aldrich. Tetrahydrofuran (THF, VWR Chemicals, 99.7\%), N,Ndimethylformamide (DMF, Merck), pyridine (J.T. Baker, 99\%), diethyl ether (VWR Chemicals, 99.5\%) were used as received. Dichloromethane (DCM, VWR Chemicals, 99.9\%) was dried and stored over 4 Å molecular sieves before use. Triethylamine (TEA, 98\%) was purchased from J.T. Baker. The poly $\left(\varepsilon\right.$-caprolactone)s with different molecular weights $\left(M_{\mathrm{n}}=6000\right.$ or $M_{\mathrm{n}}=12,000$ ) were prepared according to the literature procedure [32].

\subsection{Characterization}

All ${ }^{1} \mathrm{H}$ NMR spectra were recorded on an Agilent NMR System VNMRS 500 spectrometer at room temperature in $\mathrm{CDCl}_{3}$ with $\mathrm{Si}\left(\mathrm{CH}_{3}\right)_{4}$ as an internal standard. Molecular weights were determined by gel permeation chromatography (GPC) using 
an instrument consisting of a Viscotek GPCmax Autosampler, a pump, three ViscoGEL GPC columns (G2000H $\mathrm{HR}_{\mathrm{HR}} \mathrm{G}^{3000 \mathrm{H}_{\mathrm{HR}}}$ and $\mathrm{G} 4000 \mathrm{H}_{\mathrm{HR}}$ ), and a Viscotek differential refractive index (RI) detector with a THF flow rate of $1.0 \mathrm{~mL} \mathrm{~min}^{-1}$ at $30^{\circ} \mathrm{C}$. The RI detector was calibrated with polystyrene standards having narrow molecular weight distribution. Data were analyzed using Viscotek OmniSEC Omni-01 software. The powder X-ray diffraction (XRD) measurements were performed on a PANalytical X'Pert PRO X-ray diffractometer equipped with graphite-monochromatized Cu K $\alpha$ radiation $(\lambda=1.15 \AA)$. Differential scanning calorimetry (DSC) was performed on a Perkin-Elmer Diamond DSC with a heating rate of $20^{\circ} \mathrm{C} / \mathrm{min}$ under nitrogen flow $(20 \mathrm{~mL} / \mathrm{min}$ ). Thermogravimetric analysis (TGA) was performed on a Perkin-Elmer Diamond TA/TGA with a heating rate of $10{ }^{\circ} \mathrm{C} / \mathrm{min}$ under nitrogen flow $(200 \mathrm{~mL} / \mathrm{min})$. Transmission electron microscopy (TEM) imaging of the samples was carried out on a FEI Tecnai ${ }^{\mathrm{TM}} \mathrm{G}^{2} \mathrm{~F} 30$ instrument operating at an acceleration voltage of $200 \mathrm{kV}$. Ultrathin TEM specimens (about $100 \mathrm{~nm}$ ) were prepared by using a cryo-ultramicrotome $\left(\mathrm{EMUC}_{6}+\mathrm{EMFC}_{6}\right.$, Leica) equipped with a diamond knife. The ultrathin samples were placed on holey carbon-coated grids for TEM analyses.

\subsection{Functionalization of MMT- $\left(\mathrm{CH}_{2} \mathrm{CH}_{2} \mathrm{OH}\right)_{2}$ with succinic anhydride (MMT-COOH)}

The hydroxyl groups of the clay were converted to the acid functionalities by reacting with succinic anhydride. A $100 \mathrm{~mL}$ round-bottom flask was dried at $120^{\circ} \mathrm{C}$ for $10 \mathrm{~h}$ and flushed with nitrogen. At room temperature, $1 \mathrm{~g}$ of clay $(1.22 \mathrm{mmol}$ of OH groups calculated from TGA), $0.183 \mathrm{~g} \mathrm{SA}(1.83 \mathrm{mmol}, 1.5$ equivalent per OH group), and $0.149 \mathrm{~g}$ DMAP (1.22 mmol, 1 equivalent per $\mathrm{OH}$ group) were dissolved in $30 \mathrm{~mL}$ of dry DCM under a $\mathrm{N}_{2} .170 \mu \mathrm{L}$ TEA (1.22 mmol, 1 equivalent per $\mathrm{OH}$ group) was added and solution was stirred for $12 \mathrm{~h}$ under $\mathrm{N}_{2}$ atmosphere at room temperature. Then, solvent was evaporated under vacuum. The residue was dissolved in $50 \mathrm{~mL}$ of THF and evaporated again. The product was precipitated in $350 \mathrm{~mL}$ of cold diethyl ether under stirring. The resulting product was filtered off using a filter and washed two times with $40 \mathrm{~mL}$ of diethyl ether. After drying in reduced pressure $370 \mathrm{mg}$ of product (35\%) was obtained.

\subsection{Preparation of cyclodextrin-functionalized clay (MMT-CD)}

The acid-functionalized MMT-COOH was reacted with hydroxyl groups of cyclodextrin using DCC and DMAP as catalysts. In the procedure, the MMT-COOH was dried under vacuum at $110^{\circ} \mathrm{C}$ for $1 \mathrm{~h}$. In a $100 \mathrm{~mL}$ round-bottom flask under nitrogen flow, $0.50 \mathrm{~g}$ of MMT- $\mathrm{COOH}\left(0.61 \mathrm{mmol}\right.$, assumed that all the OH groups of MMT- $\left(\mathrm{CH}_{2} \mathrm{CH}_{2} \mathrm{OH}\right)_{2}$ were converted to $\mathrm{COOH}$ groups), $0.692 \mathrm{~g}$ of cyclodextrin ( $0.61 \mathrm{mmol}, 1$ equivalent per succinyl moiety), and $0.223 \mathrm{mg}$ of DMAP (1.80 mmol, 3 equivalent per succinyl moiety) were dissolved in $20 \mathrm{~mL}$ of dry pyridine. Then, the $0.378 \mathrm{~g}$ of DCC ( $1.83 \mathrm{mmol}, 3$ equivalent per succinyl moiety) was added after cooling the solution to $0^{\circ} \mathrm{C}$. $1 \mathrm{~h}$ later, the solution was brought to room temperature and stirred 3 days at $70^{\circ} \mathrm{C}$. Next, solvent was evaporated under vacuum, residue was partially dissolved in $5 \mathrm{~mL}$ of THF and poured into excess cold diethyl ether under vigorous stirring. After filtration, the precipitate was collected and washed two times with $20 \mathrm{~mL}$ of diethyl ether. After drying in vacuum, $360 \mathrm{mg}$ of product (40\%) was obtained as a white powder.

\subsection{Preparation of PCL/MMT nanocomposites via host-guest chemistry}

The nanocomposites were obtained by the addition of PCL into DMF solution of MMT-CD. A solution of $100 \mathrm{mg}$ poly $(\varepsilon-$ caprolactone) $\left(M_{n}=6000\right.$ or $\left.M_{n}=12,000\right)$ and MMT-CD (1\%,5\%, and $10 \%$ of the polymer by weight) partially dissolved in $10 \mathrm{~mL}$ of DMF in a flask with a magnetic stirrer was placed in an oil bath at $80^{\circ} \mathrm{C}$ for $24 \mathrm{~h}$. Next, solvent was evaporated under vacuum, residue was partially dissolved in $5 \mathrm{~mL}$ of THF and poured into excess methanol under vigorous stirring. After filtration, the precipitate was dried under vacuum. The yield was determined gravimetrically (95\%).

\section{Results and discussion}

\subsection{Functionalization of organomodified nanoclay with cyclodextrin}

Cyclodextrins (CD)s are water-soluble, crystalline, non-hygroscopic, homogeneous substances, toroidially shaped oligosaccharides built up from built from 6 to 12 glucopyranose (glucose) units. Due to their torus-like geometry with a hydrophobic cavity and a hydrophilic exterior surface, a wide variety of hydrophobic molecules or hydrophobic side groups of polymer as guests can accommodate in their cavities to form host/guest complexes. These inclusion-complexing features of CDs make them useful in many research and industrial, and environmental applications. Our concept is based on the incorporation of CDs into silicate layers of montmorillonite clay, which is suitable for inclusion-complexation with PCL via host-guest chemistry. For this purpose, the two hydroxyl groups of MMT- $\left(\mathrm{CH}_{2} \mathrm{CH}_{2} \mathrm{OH}\right)_{2}$ were reacted with succinic anhydride to form acid-functionalized clay (MMT- $\mathrm{COOH}$ ) via ring-opening reaction. Then, the $\mathrm{CD}$ molecules were attached onto MMT-COOH to obtain CD-functionalized clay (MMT-CD) through esterification reaction using DCC and DMAP as catalysts. The successful attachment of CD molecules into the clay surface was confirmed by FT-IR, TGA and XRD analyses.

The FT-IR spectrum of the obtained MMT-CD showed that a new broad peak at around $3400 \mathrm{~cm}^{-1}$ corresponding to hydroxyl groups of $\mathrm{CD}$ while the a characteristic peak at $3650 \mathrm{~cm}^{-1}$ associated with free hydroxyl group of MMT peak was still present (Fig. 1). Furthermore, the characteristics peaks at 1740, 1515 and $1330 \mathrm{~cm}^{-1}$ indicate the successful ester 
formation between MMT-COOH and CD units. In addition, the characteristic Si-O stretching band was detected in the region of $1040 \mathrm{~cm}^{-1}$. On the other hand, the XRD diffraction peaks were shifted to a lower angle (from $4.89^{\circ}$ to $4.65^{\circ}$ for $\mathrm{MMT}-\mathrm{COOH}$ and $4.65^{\circ}$ to $4.53^{\circ}$ for MMT-CD) after ring-opening and esterification reactions (Fig. 2). These results indicated that the total increase of the interlayer distance of the MMT-CD was $0.15 \mathrm{~nm}$. The degree of CD surface functionality was determined by thermal gravimetric analysis (TGA), which was performed to estimate the organic content of organomodified clays. The mass losses were determined as 20.7\%, 25.8\% and 30.3\% for MMT- $\left(\mathrm{CH}_{2} \mathrm{CH}_{2} \mathrm{OH}\right)_{2}$, MMT-COOH and MMT-CD, respectively (Fig. S1). This change indicated that the cyclodextrin unit was successfully intercalated into the silicate galleries of the MMT clay (see Table 1).

\subsection{Preparation of PCL/MMT nanocomposites via host-guest chemistry}

Exfoliation of the clay layers requires strong attractive interactions between the clay surface and polymer matrix, giving rise to enhanced compatibility between the two resulting in the formation of a highly dispersed (nearly exfoliated) nanocomposite. Four different specific interactions including ionic, ion-dipole, hydrogen bonding, and coulombic are well-known interactions between the clay surface and polymer matrix in the nanocomposites formation. Host-guest interactions involve a complementary stereoelectronic arrangement of binding sites in the host and guest sites via intermolecular forces. They vary in strength from strong electrostatic interactions, through hydrogen bonding, cation $-\pi, \pi-\pi$ stacking, and metal-ligand binding, to weak van der Waals attractions, and solvent reorganization. Due to their extremely low toxicity and good complexation capacity with a variety of lipophilic molecules, CDs are the most widely employed host units to construct assemblies with hydrophobic polymers. PCL is a biodegradable polyester that has found widespread uses as a hydrophobic block in amphiphilic synthetic block copolymers. Various inclusion complexes were prepared by the host-guest reaction between CDs ( $\alpha-, \beta$ - and $\gamma$-cyclodextrins) and PCLs with radial, conical, blocked, or linear molecular architecture [55]. In our case, well-defined PCL with different molecular weights $\left(M_{n}=6000\right.$ and $M_{n}=12,000$ coded as PCL6 and PCL12, respectively) were prepared by ring-opening polymerization of epsilon caprolactone initiated with $\mathrm{Sn}(\mathrm{Oct})_{2}$ and 1-butanol. Taking advantage of host-guest interactions between MMT-CD and PCL6 or PCL12, a series of PCL/MMT nanocomposites with various nanoclay loadings were prepared (Scheme 1) and their physical properties were collected in Table 1.

\subsection{The morphology of PCL/MMT nanocomposites}

After the nanocomposites formation, the XRD peak of MMT-CD $\left(4.53^{\circ}\right)$ disappeared in the diffraction patterns of the in both nanocomposites with 1\% loadings (PCL6-MMT-1 and PCL12-MMT-1), which indicated the formation of exfoliated structures. Besides, the PCL6-MMT-5, PCL6-MMT-10, PCL6/MMT-5 and PCL12/MMT-10 samples demonstrated small and broad peaks that might be resulting from partially exfoliated or intercalated structures with $d$-spacings of 2.05, 2.07, 2.09 and $2.11 \mathrm{~nm}$, respectively (Fig. 2). The clay concentration was an important parameter for the degree of exfoliation in the nanocomposites formation. At low clay concentration, polymer clay interactions overcame the van der Waals forces between silicate interlayers resulting in complete delamination of clay layers. Due to an increase in clay concentration, the agglomerated structures became denser in the polymer matrix and van der Waals interactions dominated polymer clay interactions resulting in a finite expansion of silicate interlayers and retention of clay structure. To further existence of this host-guest interaction between PCL chains and intercalated CD units, the following procedures were carried out. The MMT$\left(\mathrm{CH}_{2} \mathrm{CH}_{2} \mathrm{OH}\right)_{2}$, MMT-COOH and MMT-CD with 5\% loading were mixed both PCL6 and PCL12 under similar experimental conditions. According to XRD results, the $d$-spacing values of the PCL6-MMT-5-, PCL6-MMT-5-COOH and PCL6-MMT-5-CD samples were increased from 1.98, 2.01 to 2.05. In addition, the PCL12-MMT-5-, PCL12-MMT-5-COOH and PCL12-MMT-5-CD

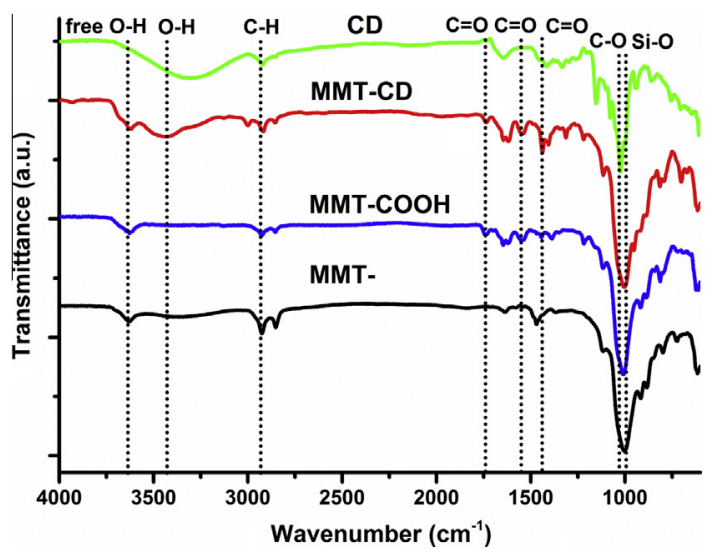

Fig. 1. FT-IR spectra of neat MMT- $\left(\mathrm{CH}_{2} \mathrm{CH}_{2} \mathrm{OH}\right)_{2}, \mathrm{CD}$, MMT-COOH and MMT-CD. 


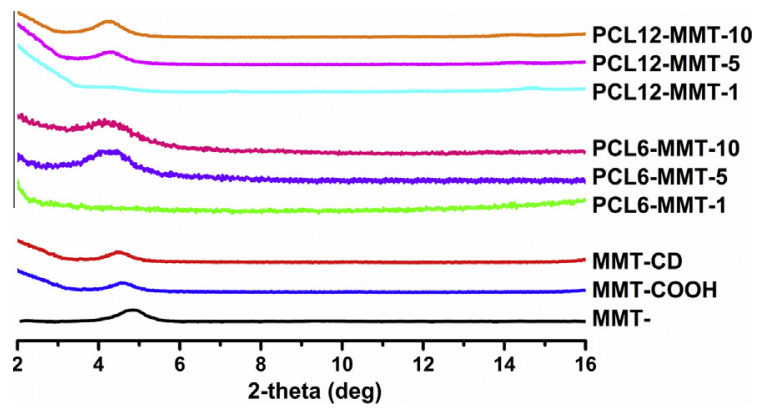

Fig. 2. X-ray diffractions of MMT- $\left(\mathrm{CH}_{2} \mathrm{CH}_{2} \mathrm{OH}\right)_{2}$, MMT-COOH and MMT-CD, and the nanocomposites (PCL6-MMT-1, PCL6-MMT-5, PCL6-MMT-10, PCL12MMT-1, PCL12-MMT-5 and PCL12-MMT-10).

samples displayed a similar trend, the values increased from 2.03, 2.06 to 2.09 (Fig. S2). These results implied that the presence of PCL/CD host-guest interactions enhance the exfoliation/intercalation ability of clay layers.

The XRD analysis is a useful tool for the description of the regularity of clay layers in the nanocomposites. But its reliability is limited due to the clay dilution, preferred orientation, mixed layering and other peak broadening factors. It has to be supported with direct imaging techniques such as atomic force microscopy or transmission electron microscopy (TEM) to define the exact nature of the clay layers in the nanocomposites formation. TEM images of selected PCL6/MMT-5 and PCL12/MMT-5 nanocomposites were presented in Figs. 3 and 4 at different magnifications. The clay layers seem as dark gray lines about 1-2 nm thick and from 50 to $100 \mathrm{~nm}$ in lateral dimension and the gray/white areas represent the polymer matrix. The high magnification TEM images (Figs. 3a and 4a) noticeably displayed that most silicate layers were exfoliated and dispersed in the polymer matrix homogenously. In addition, the some intercalated silicate layers were locally stacked in the polymer matrix. The low magnification images (Figs. 3b and 4b) showed the general dispersion of clay layers as well as their mixed morphologies including intercalated layers with a non-uniform separation and exfoliated single layers isolated from any stack in the polymer matrix. Overall, combined XRD and TEM results confirmed that partially exfoliated/intercalated structures were detected in all nanocomposites. The coexistence of mixed morphologies suggested that the van der Waals and Coulombic forces between intergalleries were still strong to hold them tightly. On the other hand, because of their high specific surface area and surface energy, the clay layers tend to aggregate together rather than to disperse homogeneously in the polymer matrix, especially at high clay loadings [30]. Therefore, it could be more difficult to overcome these intermolecular forces between clay layers and some of them could not to be delaminated completely.

\subsection{Thermal behavior of PCL/MMT nanocomposites}

Thermal properties of the nanocomposites were investigated by TGA and DSC analyses and compared with their initial polymers. The DSC studies with a heating rate of $10^{\circ} \mathrm{C} / \mathrm{min}$ under nitrogen flow were performed to determine melting temperatures $\left(T_{\mathrm{m}}\right) \mathrm{s}$ of the neat polymers and all nanocomposites samples at various clay loadings. Fig. $5 \mathrm{showed} \mathrm{that} \mathrm{samples} \mathrm{up}$ to $10 \mathrm{wt} \%$ of MMT-CD have one endothermic peak which represents melting of the crystalline phase in both PCL6 (57.5 $\left.{ }^{\circ} \mathrm{C}\right)$

Table 1

Physical properties of PCL/MMT nanocomposites and their components.

\begin{tabular}{|c|c|c|c|c|c|}
\hline \multirow[t]{2}{*}{ Entry } & \multirow[t]{2}{*}{$d_{001}^{\mathrm{a}}(\mathrm{nm})$} & \multirow[t]{2}{*}{$T_{\mathrm{m}}{ }^{\mathrm{b}}\left({ }^{\circ} \mathrm{C}\right)$} & \multicolumn{2}{|c|}{$\begin{array}{l}\text { Weight loss temperature }{ }^{\mathrm{c}} \\
\left({ }^{\circ} \mathrm{C}\right)\end{array}$} & \multirow[t]{2}{*}{ Char yield ${ }^{c}(\%)$} \\
\hline & & & $10 \%$ & $50 \%$ & \\
\hline MMT- & 1.82 & - & 569 & - & 79.2 \\
\hline MMT-COOH & 1.91 & - & 267 & - & 74.2 \\
\hline MMT-CD & 1.97 & - & 306 & - & 69.7 \\
\hline PCL6 & - & 57.5 & 344 & 389 & $<1$ \\
\hline PCL6-MMT-1 & n.d. ${ }^{\mathrm{d}}$ & 58.1 & 369 & 407 & 1.2 \\
\hline PCL6-MMT-5 & 2.05 & 58.1 & 367 & 409 & 4.9 \\
\hline PCL6-MMT-10 & 2.07 & 58.8 & 369 & 423 & 7.8 \\
\hline PCL12 & - & 63.1 & 355 & 390 & $<1$ \\
\hline PCL12-MMT-1 & n.d. ${ }^{\mathrm{d}}$ & 65.9 & 349 & 407 & 1.8 \\
\hline PCL12-MMT-5 & 2.09 & 65.7 & 362 & 411 & 5.4 \\
\hline PCL12-MMT-10 & 2.11 & 65.4 & 352 & 430 & 9.8 \\
\hline
\end{tabular}

a Basal spacing $\left(d_{001}\right)$ is calculated by XRD analysis.

b Determined by DSC and analyses under a nitrogen flow at a heating rate of $10^{\circ} \mathrm{C} / \mathrm{min}$.

c Determined by TGA analysis under a nitrogen flow at a heating rate of $10{ }^{\circ} \mathrm{C} / \mathrm{min}$.

d Probably complete exfoliated nanocomposites. 


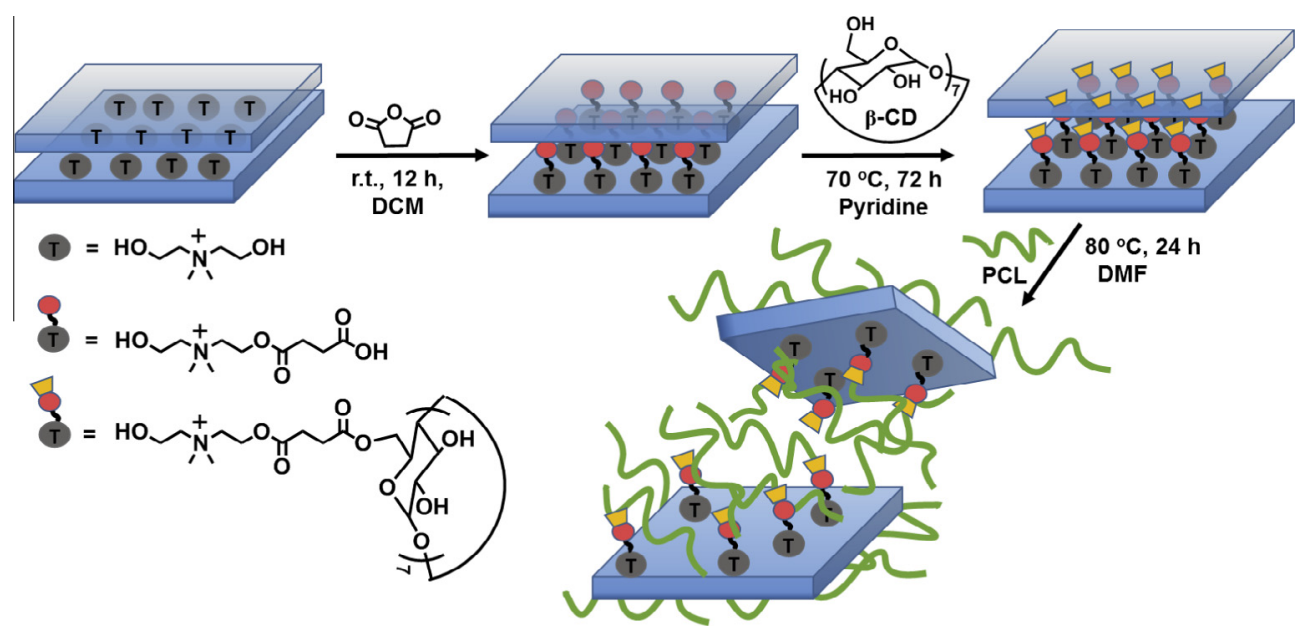

Scheme 1. Functionalization of MMT- $\left(\mathrm{CH}_{2} \mathrm{CH}_{2} \mathrm{OH}\right)_{2}$ with succinic anhydride, $\beta$-cyclodextrin and preparation of PCL/MMT nanocomposites.
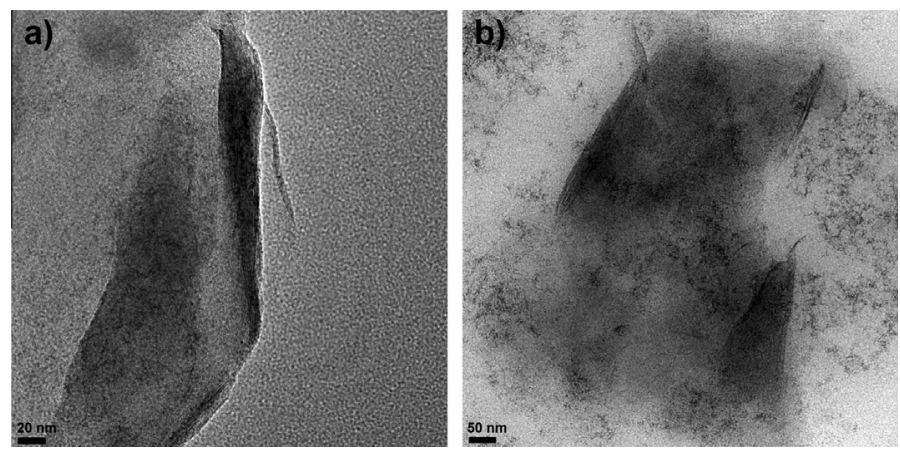

Fig. 3. TEM micrographs of PCL6-MMT-5 in high (a, scale bar: $20 \mathrm{~nm}$ ) and low (b, scale bar: $50 \mathrm{~nm}$ ) magnifications.
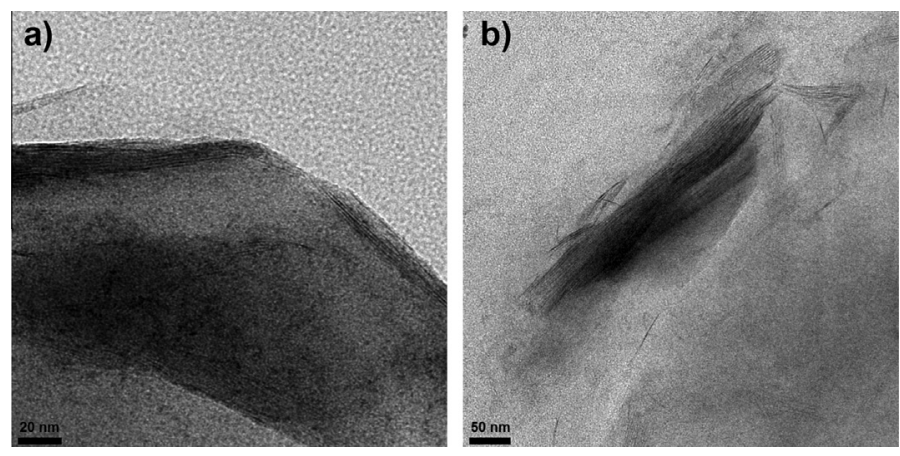

Fig. 4. TEM micrographs of PCL12-MMT-5 in high (a, scale bar: $20 \mathrm{~nm}$ ) and low (b, scale bar: $50 \mathrm{~nm}$ ) magnifications.

and PCL12 $\left(63.1^{\circ} \mathrm{C}\right)$ semi-crystalline polymers. It was founded that the presence of MMT-CD have slight effects on the $T_{\mathrm{m}}$ of the nanocomposites compared to neat polymers. By increasing clay loadings, a slight increase in $T_{\mathrm{m}}$ of the nanocomposite samples was observed. This result could be attributed to the confinement of the intercalated polymer chains within the clay galleries, which prevents the segmental motions of the polymer chains and led to accelerate crystalline structures in the nanocomposites formation. This slight increase in crystallinity has also been observed in traditional semi-crystalline polymer/clay nanocomposites. Similar behavior was reported by other groups [56,57]. It was also found that $\left(T_{\mathrm{m}}\right) \mathrm{s}$ of the PCL12 samples were remarkably higher than those of the PCL6 samples [58].

Thermal stabilities of the nanocomposites and their neat polymers were studied by TGA heating from room temperature to $900^{\circ} \mathrm{C}$ under nitrogen atmosphere to avoid thermal oxidation, determining direct correlation between chemical structure 


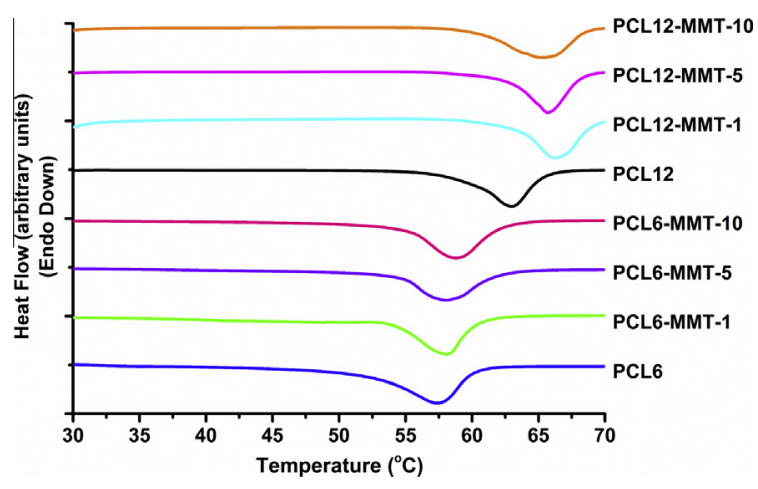

Fig. 5. DSC traces of neat PCL6 and PCL12 and resulting nanocomposites.
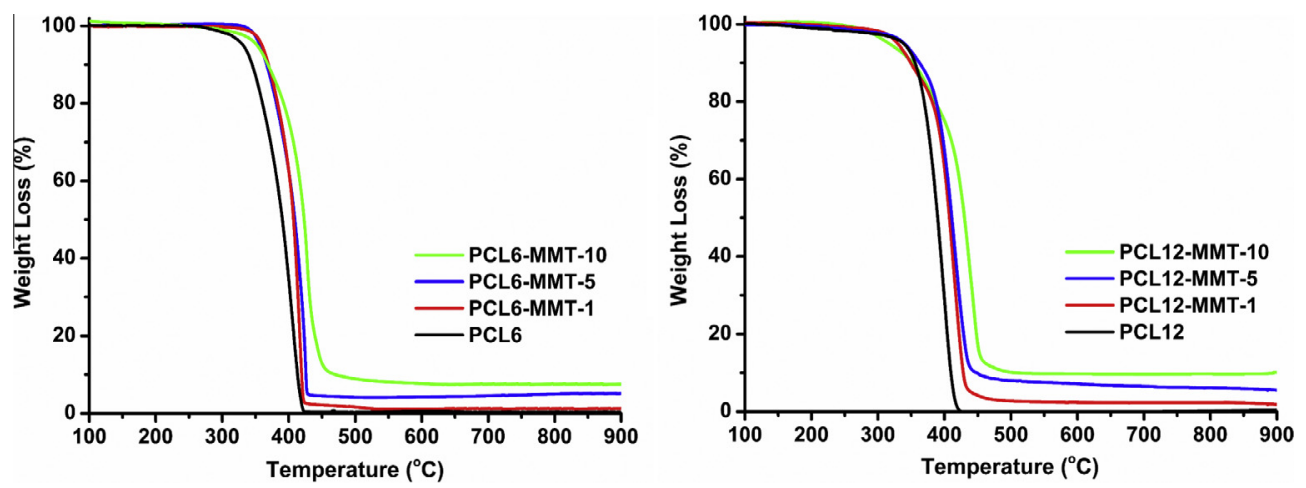

Fig. 6. TGA thermograms of neat PCL6 and PCL12 and resulting nanocomposites.

and thermal degradation. The TGA results showed that all PCL6/MMT and PCL12/MMT samples degraded through single degradation step in the temperature range $300-500{ }^{\circ} \mathrm{C}$ (Fig. 6). Thermal degradation begins at $350{ }^{\circ} \mathrm{C}$ and accelerated at $400^{\circ} \mathrm{C}$ as the PCL chains began to degrade. In order to establish the influence of the MMT-CD concentration on the thermal stability of PCL, the $T_{\text {onset }}$ (temperature at $10 \%$ weight loss) and $T_{\max }$ (temperature at $50 \%$ weight loss) were collected in Table 1 ). The $T_{\text {onset }}$ temperatures of the nanocomposite samples with different organic clay loadings were very close to each other. The $T_{\max }$ temperatures of the nanocomposites samples increased almost linearly by increasing clay contents. It was clearly found that both degradation temperatures of all nanocomposites shifted significantly toward higher temperatures compared to those of the neat PCL. Notably, the final char yields of the nanocomposites were increased from $1.2 \%$ to $7.8 \%$ for PCL6/MMT and 1.8\% to 9.8\% for PCL12/MMT by increasing clay loadings from 1\% to $10 \%$. These increase in char yields implied the reduction of the polymer's flammability and confirmed their good thermal stabilities [59].

\section{Conclusion}

The introduction of cyclodextrin with commercially available organoclay containing hydroxyl groups has been achieved by reacting the clay with a cyclic anhydride followed by esterification process. A series of PCL/MMT nanocomposites have been prepared by solution blending of PCL with different molecular weights and MMT-CD at various clay loadings. Mixed morphologies including intercalated layers with a non-uniform separation and exfoliated single layers isolated from any stacks have been confirmed for all nanocomposites by combined XRD and TEM investigations. The melting temperatures of the samples were increased by increasing clay contents, suggesting that the degree of crystallinities were affected by the restricted mobility of the chains. Thermal stabilities of the nanocomposites were improved by the addition of MMTCD. According to TGA results, $T_{\text {onset }}$ and $T_{\max }$ temperatures of the nanocomposites were greater than that of pristine polymers. Furthermore, the final char yields of the nanocomposites were increased by increasing clay loadings.

\section{Acknowledgement}

The authors would like to thank Turkish Scientific and Technological Council (TUBITAK-214Z310) for financial supports. 


\section{Appendix A. Supplementary material}

Supplementary data associated with this article can be found, in the online version, at http://dx.doi.org/10.1016/j.eurpolymj.2015.08.006.

\section{References}

[1] C. Sanchez, G. Soler-Illia, F. Ribot, T. Lalot, C.R. Mayer, V. Cabuil, Designed hybrid organic-inorganic nanocomposites from functional nanobuilding blocks, Chem. Mater. 13 (10) (2001) 3061-3083.

[2] S.S. Ray, M. Okamoto, Polymer/layered silicate nanocomposites: a review from preparation to processing, Prog. Polym. Sci. 28 (11) (2003) $1539-1641$.

[3] M. Alexandre, P. Dubois, Polymer-layered silicate nanocomposites: preparation, properties and uses of a new class of materials, Mater. Sci. Eng., R 28 (1-2) (2000) 1-63.

[4] M. Okamoto, Recent advances in polymer/layered silicate nanocomposites: an overview from science to technology, Mater. Sci. Technol. 22 (7) (2006) $756-779$.

[5] C. Oriakhi, Nano sandwiches, Chem. Br. 34 (11) (1998) 59-62.

[6] U.N. Ratnayake, B. Haworth, Polypropylene-clay nanocomposites: influence of low molecular weight polar additives on intercalation and exfoliation behavior, Polym. Eng. Sci. 46 (8) (2006) 1008-1015.

[7] M.A. Tasdelen, J. Kreutzer, Y. Yagci, In situ synthesis of polymer/clay nanocomposites by living and controlled/living polymerization, Macromol. Chem. Phys. 211 (3) (2010) 279-285.

[8] M. Aydin, M.A. Tasdelen, T. Uyar, Y. Yagci, In situ synthesis of A(3)-type star polymer/clay nanocomposites by atom transfer radical polymerization, J. Polym. Sci., Part A: Polym. Chem. 51 (24) (2013) 5257-5262.

[9] F.B. Barlas, D.A. Seleci, M. Ozkan, B. Demir, M. Seleci, M. Aydin, et al, Folic acid modified clay/polymer nanocomposites for selective cell adhesion, J. Mater. Chem., B 2 (37) (2014) 6412-6421.

[10] H. Akat, M.A. Tasdelen, F. Du Prez, Y. Yagci, Synthesis and characterization of polymer/clay nanocomposites by intercalated chain transfer agent, Eur. Polym. J. 44 (7) (2008) 1949-1954.

[11] K.D. Demir, M.A. Tasdelen, T. Uyar, A.W. Kawaguchi, A. Sudo, T. Endo, et al, Synthesis of polybenzoxazine/clay nanocomposites by in situ thermal ringopening polymerization using intercalated monomer, J. Polym. Sci., Part A: Polym. Chem. 49 (19) (2011) 4213-4220.

[12] C. Bagcioglu, S. Sen, Y. Yagci, T. Nugay, N. Nugay, Preparation of super HIPS via nanocomposite assemblies in the presence of toughener-intercalant, EPolymers 8 (1) (2008) 1119-1130.

[13] S. Sen, N. Nugay, T. Nugay, Effects of the nature and combinations of solvents in the intercalation of clay on the properties of polymer with block copolymers nanocomposites, J. Appl. Polym. Sci. 112 (1) (2009) 52-63.

[14] E. Helvacioglu, V. Aydin, T. Nugay, N. Nugay, B.G. Uluocak, S. Sen, High strength poly(acrylamide)-clay hydrogels, J. Polym. Res. 18 (6) (2011) 23412350.

[15] N. Nugay, T. Nugay, J.P. Kennedy, Minute amounts of organically modified montmorillonite improve the properties of polyisobutylene-based polyurethanes, J. Polym. Sci., Part A: Polym. Chem. 51 (19) (2013) 4076-4087.

[16] C. Altinkok, T. Uyar, M.A. Tasdelen, Y. Yagci, In situ synthesis of polymer/clay nanocomposites by type II photoinitiated free radical polymerization, J. Polym. Sci., Part A: Polym. Chem. 49 (16) (2011) 3658-3663.

[17] A. Oral, M.A. Tasdelen, A.L. Demirel, Y. Yagci, Poly(cyclohexene oxide)/clay nanocomposites by photoinitiated cationic polymerization via activated monomer mechanism, J. Polym. Sci., Part A: Polym. Chem. 47 (20) (2009) 5328-5335.

[18] G. Malucelli, R. Bongiovanni, M. Sangermano, S. Ronchetti, A. Priola, Preparation and characterization of UV-cured epoxy nanocomposites based on omontmorillonite modified with maleinized liquid polybutadienes, Polymer 48 (24) (2007) 7000-7007.

[19] A. Di Gianni, R. Bongiovanni, L. Conzatti, S. Turri, New fluorinated montmorillonites for the preparation of UV-cured coatings, J. Colloid Interface Sci. 336 (2) (2009) 455-461.

[20] A. Nese, S. Sen, M.A. Tasdelen, N. Nugay, Y. Yagci, Clay-PMMA nanocomposites by photoinitiated radical polymerization using intercalated phenacyl pyridinium salt initiators, Macromol. Chem. Phys. 207 (9) (2006) 820-826.

[21] C. Dizman, S. Ates, T. Uyar, M.A. Tasdelen, L. Torun, Y. Yagci, Polysulfone/clay nanocomposites by in situ photoinduced crosslinking polymerization, Macromol. Mater. Eng. 296 (12) (2011) 1101-1106.

[22] K. Jlassi, M. Benna-Zayani, M.M. Chehimi, Y. Yagci, Efficient photoinduced In situ preparation of clay/poly(glycidyl methacrylate) nanocomposites using hydrogen-donor silane, J. Polym. Sci., Part A: Polym. Chem. 53 (6) (2015) 800-808.

[23] Z. Yenice, M.A. Tasdelen, A. Oral, C. Guler, Y. Yagci, Poly(styrene-b-tetrahydrofuran)/clay nanocomposites by mechanistic transformation, J. Polym. Sci., Part A: Polym. Chem. 47 (8) (2009) 2190-2197.

[24] K. Boukerma, J.Y. Piquemal, M.M. Chehimi, M. Mravcakova, M. Omastova, P. Beaunier, Synthesis and interfacial properties of montmorillonite/ polypyrrole nanocomposites, Polymer 47 (2) (2006) 569-576.

[25] Z. Salmi, K. Benzarti, M.M. Chehimi, Diazonium cation-exchanged clay: an efficient, unfrequented route for making clay/polymer nanocomposites, Langmuir 29 (44) (2013) 13323-13328.

[26] K. Jlassi, A. Mekki, M. Benna-Zayani, A. Singh, D.K. Aswal, M.M. Chehimi, Exfoliated clay/polyaniline nanocomposites through tandem diazonium cation exchange reactions and in situ oxidative polymerization of aniline, RSC Adv. 4 (110) (2014) 65213-65222.

[27] E.P. Giannelis, Polymer layered silicate nanocomposites, Adv. Mater. 8 (1) (1996) 29-35.

[28] M.A. Tasdelen, W. Van Camp, E. Goethals, P. Dubois, F. Du Prez, Y. Yagci, Polytetrahydrofuran/clay nanocomposites by in situ polymerization and "click" chemistry processes, Macromolecules 41 (16) (2008) 6035-6040.

[29] A. Oral, M.A. Tasdelen, A.L. Demirel, Y. Yagci, Poly(methyl methacrylate)/clay nanocomposites by photoinitiated free radical polymerization using intercalated monomer, Polymer 50 (16) (2009) 3905-3910.

[30] M.A. Tasdelen, Poly(epsilon-caprolactone)/clay nanocomposites via "click" chemistry, Eur. Polym. J. 47 (5) (2011) $937-941$.

[31] M. Aydin, M.A. Tasdelen, T. Uyar, S. Jockusch, N.J. Turro, Y. Yagci, Polystyrene/clay nanocomposites by atom transfer radical nitroxide coupling chemistry, J. Polym. Sci., Part A: Polym. Chem. 51 (5) (2013) 1024-1028.

[32] M. Aydin, T. Uyar, M.A. Tasdelen, Y. Yagci, Polymer/clay nanocomposites through multiple hydrogen-bonding interactions, J. Polym. Sci., Part A: Polym. Chem. 53 (5) (2015) 650-658.

[33] J. Szejtli, Introduction and general overview of cyclodextrin chemistry, Chem. Rev. 98 (5) (1998) 1743-1753.

[34] K. Kano, R. Nishiyabu, T. Asada, Y. Kuroda, Static and dynamic behavior of 2:1 inclusion complexes of cyclodextrins and charged porphyrins in aqueous organic media, J. Am. Chem. Soc. 124 (33) (2002) 9937-9944.

[35] Y. Guo, S. Guo, J. Ren, Y. Zhai, S. Dong, E. Wang, Cyclodextrin functionalized graphene nanosheets with high supramolecular recognition capability: synthesis and host-guest inclusion for enhanced electrochemical performance, ACS Nano 4 (7) (2010) 4001-4010.

[36] T. Auletta, B. Dordi, A. Mulder, A. Sartori, S. Onclin, C.M. Bruinink, et al, Writing patterns of molecules on molecular printboards, Angew. Chem. Int. Ed. 43 (3) (2004) 369-373.

[37] Y. Liu, H. Wang, P. Liang, H.Y. Zhang, Water-soluble supramolecular fullerene assembly mediated by metallobridged beta-cyclodextrins, Angew. Chem. Int. Ed. 43 (20) (2004) 2690-2694. 
[38] K. Miyake, S. Yasuda, A. Harada, J. Sumaoka, M. Komiyama, H. Shigekawa, Formation process of cyclodextrin necklace - analysis of hydrogen bonding on a molecular level, J. Am. Chem. Soc. 125 (17) (2003) 5080-5085.

[39] G. Chen, M. Jiang, Cyclodextrin-based inclusion complexation bridging supramolecular chemistry and macromolecular self-assembly, Chem. Soc. Rev. 40 (5) (2011) 2254-2266.

[40] Q. Zhang, G.-Z. Li, C.R. Becer, D.M. Haddleton, Cyclodextrin-centred star polymers synthesized via a combination of thiol-ene click and ring opening polymerization, Chem. Commun. 48 (65) (2012) 8063-8065.

[41] M. Nakahata, Y. Takashima, H. Yamaguchi, A. Harada, Redox-responsive self-healing materials formed from host-guest polymers, Nat. Commun. (2011) 2 .

[42] B.V.K.J. Schmidt, M. Hetzer, H. Ritter, C. Barner-Kowollik, Miktoarm star polymers via cyclodextrin-driven supramolecular self-assembly, Polym. Chem. 3 (11) (2012) 3064-3067.

[43] M. Osaki, Y. Takashima, H. Yamaguchi, A. Harada, An artificial molecular chaperone: poly-pseudo-rotaxane with an extensible axle, J. Am. Chem. Soc. 129 (46) (2007) 14452-14457.

[44] Y. Takashima, K. Sakamoto, Y. Oizumi, H. Yamaguchi, S. Kamitori, A. Harada, Complex formation of cyclodextrins with various thiophenes and their polymerization in water: preparation of poly-pseudo-rotaxanes containing poly(thiophene)s, J. Incl. Phenom Macrocycl. Chem. 56 (1-2) (2006) 45-53.

[45] O. Jazkewitsch, H. Ritter, Formation and characterization of inclusion complexes of alkyne functionalized poly(epsilon-caprolactone) with betacyclodextrin. Pseudo-polyrotaxane-based supramolecular organogels, Macromolecules 44 (2) (2011) 375-382.

[46] H.N. Xiao, N. Cezar, Cationic-modified cyclodextrin nano sphere/anionic polymer as flocculation/sorption systems, J. Colloid Interface Sci. 283 (2) (2005) 406-413.

[47] D.R. Yei, S.W. Kuo, H.K. Fu, F.C. Chang, Enhanced thermal properties of PS nanocomposites formed from montmorillonite treated with a surfactant/cyclodextrin inclusion complex, Polymer 46 (3) (2005) 741-750.

[48] R. De Lisi, G. Lazzara, S. Milloto, N. Muratore, Adsorption of a dye on clay and sand. Use of cyclodextrins as solubility-enhancement agents, Chemosphere 69 (11) (2007) 1703-1712.

[49] A. Ciobanu, S. Ruellan, I. Mallard, D. Landy, C. Gennequin, S. Siffert, et al, Cyclodextrin-intercalated layered double hydroxides for fragrance release, J. Incl. Phenom Macrocycl. Chem. 75 (3-4) (2013) 333-339.

[50] H.T. Zhao, G.F. Vance, Molecular inclusion properties of hydrophobic organic compounds by a modified beta-cyclodextrin intercalated within a layered double hydroxide, J. Inclusion Phenom. Mol. Recognit. Chem. 31 (4) (1998) 305-317.

[51] G. Jozefaciuk, A. Muranyi, E. Fenyvesi, Effect of cyclodextrins on surface and pore properties of soil clay minerals, Environ. Sci. Technol. 35 (24) (2001) 4947-4952.

[52] L. Mohanambe, S. Vasudevan, Structure of a cyclodextrin functionalized anionic clay: XRD analysis, spectroscopy, and computer simulations, Langmuir 21 (23) (2005) 10735-10742.

[53] Y. Qin, C. Zou, X. Yan, Y. Liu, L. Li, Performance of cationic beta-cyclodextrin as a clay stabilizer for use in enhanced oil recovery, Starch-Starke 66 (9-10) (2014) 795-801.

[54] T.S. Anirudhan, S. Sandeep, P.L. Divya, Synthesis and characterization of maleated cyclodextrin-grafted-silylated montmorillonite for the controlled release and colon specific delivery of tetracycline hydrochloride, RSC Adv. 2 (25) (2012) 9555-9564.

[55] J.W. Chung, T.J. Kang, S.-Y. Kwak, Supramolecular self-assembly of architecturally variant $\alpha$-cyclodextrin inclusion complexes as building blocks of hexagonally aligned microfibrils, Macromolecules 40 (12) (2007) 4225-4234.

[56] B. Lepoittevin, M. Devalckenaere, N. Pantoustier, M. Alexandre, D. Kubies, C. Calberg, et al, Poly( $\varepsilon$-caprolactone)/clay nanocomposites prepared by melt intercalation: mechanical, thermal and rheological properties, Polymer 43 (14) (2002) 4017-4023.

[57] D. Homminga, B. Goderis, I. Dolbnya, H. Reynaers, G. Groeninckx, Crystallization behavior of polymer/montmorillonite nanocomposites. Part I. Intercalated poly(ethylene oxide)/montmorillonite nanocomposites, Polymer 46 (25) (2005) 11359-11365.

[58] Y.P. Huang, X. Xu, X.L. Luo, D.Z. Ma, Molecular weight dependence of the melting behavior of poly(epsilon-caprolactone), Chin. J. Polym. Sci. 20 (1) (2002) 45-51.

[59] A. Leszczyńska, J. Njuguna, K. Pielichowski, J.R. Banerjee, Polymer/montmorillonite nanocomposites with improved thermal properties: Part I. Factors influencing thermal stability and mechanisms of thermal stability improvement, Thermochim. Acta 453 (2) (2007) 75-96. 